\title{
“TODAS ESTAS MONTAÑAS NOS HABLAN". Apariciones, ENGaños y SUEÑos de las MUJERES \\ EN LOS ANDES PERUANOS
}

\author{
“All this Mountains Talk to Us". \\ Apparitions, Deceits and Dreams of Women \\ in the Peruvian Andes
}

\begin{abstract}
Arianna Cecconi ${ }^{1}$
Resumen. Este artículo explorará la tenue frontera entre sueños, visiones, apariciones, encantos y engaños que experimentan las comuneras en la región de Ayacucho - Andes peruanos- cuando se alejan de sus comunidades para dirigirse solas a las montańas donde pastorean a los animales. Nos acercaremos a la divinidad de la montaña, $A p u$, considerada una de las responsables de estas apariciones e investigaremos acerca de las relaciones que las comuneras entablan con esta divinidad. Las distintas experiencias visionarias — que parecen poder provocar que las comuneras se pierdan en las montańas, se embaracen o enfermen - serán analizadas en este artículo con atención a aspectos de la percepción, su interpretación y su "uso social". La experiencia del sueño, el extraviarse y desaparecer en las montańas, llevará inevitablemente a rememorar el tiempo reciente de violencia política, cuando la experiencia mítica del desaparecer se convirtió en trágica realidad para

\footnotetext{
${ }^{1}$ Doctora en Antropología por la Escuela de Altos Estudios en Ciencias Sociales de París y la Universidad de Milán. Temas de investigación: los sueños, prácticas rituales, las formas de transmisión de la memoria y el proceso de elaboración de la violencia, entre otros.

Correo elecrónico: ariannacecconi@hotmail.com

Traducción del original inédito en italiano: Anna María Garza Caligaris.

Fecha de recepción: 0408 17; Fecha de aceptación: 2609 17; Traducción: 011217.
}

(cc) EY-NC-ND Páginas 87-116. 
miles de habitantes de la región de Ayacucho, epicentro del conflicto armado entre el movimiento maoísta Sendero Luminoso y el ejército peruano en las décadas de los ochenta y noventa del siglo pasado.

Palabas clave: sueños, Andes peruanos, apariciones, encantos, violencia.

Abstract: This paper will explore the thin boundary between dreams, visions, apparitions, charms and deceptions experienced by women of communities in the Ayacucho region - Peruvian Andes-, when they leave their communities alone, taking their animals to graze in the mountains. We will approach the divinity of the mountain, the $A p u$, considered one of the entities responsible for these visions, and we will study the relationship women develop with it. The different visionary experiences, which seem to make them get lost in the mountains, get pregnant or sick, will be examined, and attention will be paid to perceptive aspects, as well as to their interpretation and their "social use". The dream experience, getting lost and disappearing in the mountains, inevitably evokes recent times of political violence, when the mythical experience of disappearing became a tragic reality for thousands of inhabitants of the Ayacucho region, epicenter of the armed conflict between the Maoist movement Sendero Luminoso and the Peruvian army in the decades of the eighties and nineties of the last century.

Keywords: dreams, peruvian Andes, apparitions, enchantments, violence.

Cuando nos alejamos de la comunidad de Contay, ${ }^{2}$ situada a una altura de tres mil metros en los Andes peruanos, aumenta la posibilidad de encontrar al $A p u$ - la divinidad de la montaña —. ${ }^{3}$ Son sus apariciones

${ }^{2}$ La investigación etnográfica se desarrolló durante 18 meses en total, desde julio del 2004 hasta julio del 2010, en diferentes estancias en dos comunidades campesinas, Contay y Chihua, de la región de Ayacucho y en el contexto urbano de Huanta y de Ayacucho.

${ }^{3}$ El culto de los Apu está íntimamente ligado a la geografía local y cada comunidad campesina tiene la propia montaña de referencia. Existe una jerarquía entre los $A p u$ representados por los cargos del gobierno local y regional (Favre, 1967). Los Apu más bajos — menos potentes— son considerados "alcaldes", mientras Apu Raswuilka, el más importante de la región, es llamado "el presidente". 
las que contribuyen a definir la oposición entre las "tierras altas", es decir, del espacio poblado por las divinidades, la puna, y las "tierras bajas", bajo el control de los seres humanos (Molinié, 1992).

Apu, Wamani, Urqu Tayta, patrones, ángeles, dioses, espíritus, son formas distintas de nombrar a la montaña; pero al usar la palabra divinidad los comuneros no se refieren a una entidad trascendente de contornos definidos, sino más bien a una presencia inmanente en constante relación con los seres humanos (Absi, 2003). El principio del ayni - reciprocidad-, elemento central de intercambio en las comunidades campesinas, regula también las relaciones entre los comuneros y la montaña, "todo el universo es un ayni". El Apu protege a los comuneros y a sus animales cuando se quedan solos en los altiplanos; a cambio de esta protección, los pastores deben ofrecerle un "pagapu”, una "mesa ritual” — una ofrenda.

Para hablar con el $A p u$, los habitantes de Contay y Chihua recurren a la mediación de los camayos, curanderos que tienen el poder de llamarlo y consultarlo. Los sueños, por otra parte, son una de las maneras en las que el $A p u$ se manifiesta cuando él mismo decide comunicarse con las personas. Sońar con el $A p u$ es una experiencia común en las comunidades andinas y constituye un continuum entre la sociedad contemporánea y la prehispánica.

Algunos documentos de la época colonial (Guaman Poma, 1936: 282; Arriaga, 1968: 206; Cobo, 1653, 2: 227) testimonian que el sueño en el mundo andino se percibía como un mensaje que provenía de las divinidades o era generado por lugares y objetos, de ahí nacía la inseguridad y el temor de dormirse en lugares peligrosos (Borja, 1961). En el Estado incaica existían especialistas en sueños, los musquq soñadores- que daban consulta para descifrar los mensajes oníricos y hacer pronósticos. El entrecruce semántico entre la palabra quechua musquy — soñar- y musyay — adivinar- parece indicar, también en el plano lingüístico, una fuerte relación entre la experiencia del sueño y la adivinación (Taylor, 2002: 267). Los evangelizadores se percataron del papel que tenían los sueños en la religión autóctona, por eso en el Tercer Concilio Limense, que tuvo lugar en Perú (15821584), las autoridades exigían a los indígenas recién conversos dejar 
de interrogarse acerca del significado de sus sueños: "No habéis de dar crédito a sueños" - Ama moscoyta yupaychanquichicchu—, mandaban ellos, "porque los sueños son mentiras" — moscoyca yancallan, manan yupaychaypacchu (Mannheim, 1987).

Siglos de evangelización y campañas de "extirpación de idolatrías" no han conseguido todavía disolver la íntima relación entre la dimensión del sueño y la adivinación. Actualmente en las comunidades de Chihua y Contay el verbo "musquy" se utiliza poco, más bien, es el verbo español "soñar", en quechua "suynuy", el que se emplea generalmente para indicar la acción de soñar, y puede referirse a las experiencias que se desarrollan en el sueño, así como a las visiones experimentadas en estado de vigilia.

Ni en la comunidad de Chihua ni en la de Contay encontré verdaderos especialistas en los sueños, tampoco una teoría única que explicara su origen; aunque todos concuerdan en que tanto las divinidades andinas, Apu y Pachamama, como las católicas, Virgen y santos, visitan a los seres humanos en los sueños y les entregan mensajes y revelaciones. ${ }^{5}$

Existe una suerte de calendario onírico asociado al calendario ritual y festivo: un mismo sueño puede ser interpretado de forma diferente de acuerdo con las circunstancias y los tiempos en que se manifiesta. Si el sueño acontece en una fecha cercana a la fiesta del santo patrón o de la Virgen, serán sobre todo ellos quienes se aparecerán a los comuneros; mientras que si ocurre en el mes de agosto — el mes en que se celebran la mayoría de los ritos agrícolas y las "herranza" - serán la Pachamama y el $A p u$ las divinidades que se manifestarán en sus sueños.

El lugar donde se duerme o los lugares que se han visitado antes de entregarse al sueño son variables importantes. Cuando los comuneros

\footnotetext{
${ }^{4}$ Sermón XIX, en que se reprehenden los hechiceros y sus supersticiones y ritos vanos", del "Tercero cathecismo y exposición de la doctrina christiana por sermones", en "Tercero Concilio Limense. Doctrina christiana y catecismo para instruccón de indios”. Facsímil del texto trilingue. Consejo Superior de Investigaciones Cientificas, Madrid, 1985 [1585], p. 574.

[Nota de traducción: disponible en http://www.mscperu.org/teologia/1historia/1era\%20EvangAL/documentos1EvaAL/Tercer_CatecismoCLIII.htm].

${ }^{5}$ Las apariciones oníricas de la divinidad reflejan la presencia de un panteón religioso heterogéneo, que se creó y se transformó en lo que el historiador Serge Gruzinski (1988) ha designado "la colonización del imaginario", proceso que ha caracterizado el encuentro de españoles e indios desde la época de la conquista.
} 
van a pastorear los animales o cuando se duermen en la Puna, es probable que sean visitados por el $A p u$; cuando van a una iglesia o están en una romería, es posible que las visitas a la Virgen o a algún santo sean correspondidas por una aparición onírica. Un acontecimiento en la vida diurna se considera una circunstancia que predispone a un cierto tipo de sueño: en estos casos, se trata de un "presagio de un sueño" (Robin, 2008), más que un "sueño premonitor".

No todos los sueños están asociados a la revelación. Hay sueños con "pensamientos" producto de las preocupaciones cotidianas o causados por haber comido o bebido demasiado, son sueños que no tienen importancia. Las revelaciones de las divinidades se caracterizan por una intensidad mayor, tanto que al despertar persisten en la memoria de quien sueña o son reconocidas como tal más adelante, cuando se cumplen. ${ }^{6}$

Las razones por las que el $A p u$ se manifiesta en los sueños de los comuneros son múltiples, por ejemplo para avisarles que los animales se han extraviado en las montañas, también para amenazarlos o castigar a quien se ha olvidado de hacerle una ofrenda ritual — pagapu—, así como para curar o para engañar.

Sobre las formas y consecuencias de las seducciones se enfocará la primera parte de este artículo. En la segunda parte, exploraremos las interpretaciones que se dan a estas experiencias oníricas y su uso social. Las narraciones míticas y los sueńos serán puestos en la perspectiva de los acontecimientos históricos, en particular con la guerra entre el movimiento maoísta Sendero Luminoso y el ejército peruano (1982-1992), que afectó profundamente a las comunidades andinas en la región de Ayacucho donde se ha llevado a cabo esta investigación.

\section{Las formas del engaño}

El Apu puede aparecerse a los habitantes de Chihua y Contay bajo la apariencia de algún animal como el cóndor, un pájaro-divinidad muy importante en la cosmología incaica, o el toro, animal traído por los españoles. Pero cuando el $A p u$ quiere seducir aparece en general bajo

\footnotetext{
${ }^{6}$ Los sueños significativos pueden estar asociados a la salida del animu-anima del cuerpo de la persona, lo cual le permite ver y vivir las cosas antes de que sucedan.
} 
la apariencia de un "gringo", un hombre blanco, bien vestido, con la apariencia de los grandes propietarios de tierras — hacendados ${ }^{7}$ que hasta los ańos 1970-1980 detentaban el poder en estas tierras. ${ }^{8}$

Si bien el $A p u$ se presenta en los sueños de las comuneras, así como en los de los comuneros — en estos últimos casos bajo la forma de una mujer "gringa"-, en esta investigación me acerqué a los sueños de las mujeres. ${ }^{9}$ En Chihua y en Contay viví con familias de comuneras que se habían quedado viudas durante el conflicto armado, con ellas en particular compartí los días y el cuarto para dormir. Además, por mi posición de mujer soltera preferí conocer a los comuneros varones a través de la mediación femenina. Tal como con frecuencia me hacían notar las mujeres de Chihua y Contay, yo no conocía las técnicas de seducción que se practican en aquellos lugares y debía cuidarme tanto de los hombres como del $A p u$. Además, más allá de mi mayor cercanía a ellas, me di cuenta que la atención y el compartir experiencias oníricas era, sobre todo, una práctica del ámbito femenino. ${ }^{10}$ Con frecuencia

${ }^{7}$ Las haciendas, grandes propiedades de tierra, fueron una presencia permanente que conectaba
centro y periferia y representaban el canal mediante el cual el Estado podía alcanzar y controlar
a la mayor parte de la población rural. Con la reforma agraria del general Velasco en 1968,
el sistema de hacienda fue oficialmente abolido, aun cuando en la comunidad de Contay la hacienda de Pariabamba siguió existiendo hasta la década de 1980.

${ }^{8}$ Según el antropólogo Favre (1967), los Apu son generalmente considerados entidades masculinas y cada montaña está a su vez asociada a una laguna - qocha- que representaría el elemento femenino. Sin embargo, en las comunidades de Chihua y de Contay he encontrado muchas referencias a montańas femeninas: "Antarcacca es mujer. En tu sueño siempre se viste con ropa negra, con un sombrero blanco, así [se] te revela".

${ }^{9}$ Casi todos los sueños fueron narrados oralmente en español o en quechua. Algunos sueños fueron contados durante el curso de largas entrevistas a profundidad, mientras que de algunas mujeres he recogido una "biografía onírica" en las que el recuerdo de los sucesos surgidos en su vida se intercalaba con narraciones de sueños ligados a esos episodios. Otros sueños, más bien, emergieron de improviso en conversaciones cotidianas, mientras se hablaba o se hacía otra cosa. En esos casos, al no poder registrar ni anotar en detalle la trama del sueño, se perdió la riqueza de aquellas narraciones oníricas, pero el contexto, las motivaciones y las explicaciones del relato manifestaron a menudo la fluida continuidad entre la vida diurna y la nocturna.

${ }^{10}$ El soñar podría ser visto como parte de aquellas habilidades intuitivas que según los antropólogos Carmen Escalante y Ricardo Valderrama (1997) son asociadas, en el contexto andino, sobre todo a las mujeres. Esto parece depender también de las condiciones de vida y de la educación que las mujeres han recibido. A menudo los campesinos y pastores de la Puna en el pasado y hoy emprenden largos viajes fuera de la comunidad para vender o intercambiar productos. Esta condición de lejanía podría ser, según los dos autores, uno de los factores que lleva a las mujeres a desarrollar una habilidad para oír a la distancia — y en esto los sueńos ocupan 
las comuneras se quejaban de que los hombres no daban suficiente importancia a los sueños.

Para comprender las técnicas de seducción del $A p u$ ha sido necesario primero explorar la relación de pareja en los pueblos andinos. Los cortejos y los primeros enamoramientos entre jóvenes se llevan a cabo en la soledad del altiplano, lejos de la mirada de los adultos. Los jóvenes se conocen mientras pastorean los animales y empiezan los juegos de seducción — tirarse guijarros, silbarse, robarse prendas y perseguirse uno a otro-, juegos que a veces se convierten en encuentros sexuales reales. Las fiestas de la comunidad también son ocasión para que los jóvenes aún solteros se cortejen y bailen; no es casual que nueve meses después de las festividades de Carnaval y del santo patrono nazcan algunos niños en las comunidades. Cuando las chicas quedan embarazadas sin tener compañero o marido, el hijo crece en la familia de la madre, lo que no elimina de forma definitiva las posibilidades de que las jóvenes se casen más adelante. Sin embargo, la libertad sexual de la adolescencia termina apenas se forma una pareja formal.

Las comuneras ahora abuelas recuerdan que hace tiempo la vida en pareja empezaba temprano - generalmente, a partir de los 14 años-y esta decisión no era ni libre ni personal, sino impuesta por la familia. Hoy día en las comunidades andinas los matrimonios concertados son raros y la vida formal de pareja también se ha pospuesto. Las jóvenes comuneras hablan sobre el amor y el matrimonio de una manera distinta de como lo hacían sus madres; sin embargo, en sus discursos las mujeres de diversas generaciones utilizan de forma recurrente la palabra "engaño" para evocar las técnicas de seducción puestas en práctica tanto por los hombres como por las divinidades.

Las chicas cuentan que cuando sus coetáneos quieren seducirlas las engañan con falsas promesas o intentan emborracharlas. El "engaño" suele estar relacionado con una distorsión de la información o con la pérdida de control provocada por el alcohol. Para engañar, el $A p u$ parece utilizar técnicas de cortejo semejantes a las de los humanos. El $A p u$ aparece en los sueños y bajo la apariencia de un gringo hace

un lugar central- si sus parientes se encuentran bien o en situaciones difíciles (Escalante y Valderrama, 1997: 157). 
promesas: "Ven conmigo, me gustas, te voy a dar cualquier cosa que quieras, cualquier regalo, todos los animales que desees". Otras veces se manifiesta de manera inefable: cuando las comuneras se encuentran solas en las montañas tienen la sensación de perder el sentido de orientación o experimentan distintas sensaciones como el sentirse golpeadas por un guijarro, oírse llamadas, ser empujadas o perseguidas, cuando en realidad no hay nadie, lo cual puede ser interpretado como manifestaciones del engaño del $A p u$.

En la familia que me hospedaba en Contay, la hija, Alicia, y también la madre, Damasina, me contaron haber vivido intentos de seducción del espíritu de la montańa. El Apu se manifestó a Damasina por primera vez cuando la seńora ya estaba casada. Damasina estaba pastoreando las ovejas cuando empezó a llover y decidió refugiarse en una gruta. Cuenta que de repente sintió la presencia de alguien detrás de ella que le tocaba la espalda, aterrada huyó y apenas llegó a casa contó todo a su esposo.

Aquella misma noche, un señor de cierta edad, blanco, alto y de ojos azules, con un sombrero negro y un poncho, la visitó en sueño, la reprendió por haber dicho al marido lo sucedido. De ese día en adelante aquel personaje, que según ella era una personificación del $A p u$, empezó a perseguirla en sueños, intentando seducirla, y le prometió riquezas; así también predijo la muerte prematura de su esposo - acontecimiento que ocurrió en los años siguientes - " "En mis sueños me perseguía, era de ojos claros, rubio. Era como tío Santiago. Él parecía un gringo rubio. Todas las noches sin cesar me perseguía por todos lados, hasta en la pared de arriba me perseguía. ¡Anda mira!”. Tal vez tu padre despertaba: "Este hombre me está persiguiendo", yo decía. “¿Te persigue en tus sueños?”, "Sí, pues". ${ }^{11}$

El Apu apareció también a su hija, Alicia, cuando la joven tenía diecisiete años. Alicia cuenta que eran alrededor de las siete de la noche y ella había ido a controlar el canal de riego que debía llevar agua al molino donde su madre había llevado trigo. Del otro lado del río apareció de repente un hombre blanco, bien vestido, que le pidió lo

11 “... qatikachawaptin tudo suyñuyniypi, uqi ñawi, blanco. Tiyuyki Santiago chaynam karqa, blanco gringoniraqmi karqa. Puraminti tutan-tutan qatikachawan, tukuy kay, hanay wasi pirqa, chaypi qatikachawan. Yawya! Talvez papayki rikcharirun, kay runam qatikachawachkan" nispay. "Suyñuyniykipi qatikachasunki?". "Awriki ...”. 
siguiera. En seguida, el hombre desapareció y Alicia huyó hacia molino donde estaba su madre. No dijo nada y aquella misma noche soñó con aquel hombre que le declaraba su amor y le dijo que la esperaría en el lugar donde se habían encontrado. De ese día en adelante los sueños con el gringo se volvieron recurrentes. Damasina y Alicia aluden a un continuum entre la visión tenida cuando se encontraban solas en las montañas y sus sueños nocturnos repetitivos. Damasina y Alicia interpretan estas experiencias como un intento de engaño del $A p u$.

La aparición de objetos gratos — naranjas, queso, verdura, flores- también se considera una forma de engaño, "para engañarte Urq Tayta te hace alucinar, te hace ver naranjas, camotes, pepinos, te aparecen cosas, luego, cuando entras para recogerlos, te engaña"12. "Te aparece cosas $[\ldots]$ "13, una suerte de ilusión andina que atrae a las jóvenes hacia algunos lugares, grutas de la montaña, y que desaparece en cuanto se acercan.

Puesto que el cuerpo humano se percibe como un lugar poroso, abierto, cuyos orificios - la boca, los ojos, las orejas, el ano, la "mollera" de la cabeza - son puertas por medio de las cuales las almas o los agentes externos entran y salen, así se utiliza una metáfora corpórea para describir la montańa: los lagos son los ojos por medio de los cuales el Apu puede ver, las grutas — kamarin, Machay — son consideradas bocas donde los campesinos depositan ofrendas rituales, y en relación con las bocas-puertas el $A p u$ parece manifestarse con más frecuencia.

- ¿Alguien te contó sobre el padre cerro?

- Mi madre me contaba

- ¿Cómo te contaba?

—Dice que, este ... iba en una neblina densa. Una muchacha dice que iba. Ahora ya está muerta, pues, está muerta, no vive. La muchacha dice que iba en la neblina, aún era muy joven, de unos trece ańos, doce, más o menos. Entonces [el cerro] la engañó a ella.

- ¿Cómo fue?

\footnotetext{
12 "Ingańusunki urqutayta ima kunapas rikurisunki naranqakunapas, camote, kulispas rikuriramusunki, qinaptin chayta pallaykuy raykuruptiki ingañusunki”.

13 "Ima kunapas rikurisunki".
} 
-Este ... había un señor con sombrero fino. Salió de una puerta que había en el cerro y la metió allí (Rosa, Contay).

El tema de la seducción divina ocupa un lugar central en las narraciones míticas que encontramos en crónicas coloniales y que siguen circulando hoy en día en varias regiones del Perú. En muchos mitos el $A p u$ enamorado se manifiesta bajo la apariencia de un hombre atractivo que intenta engañar a la joven y en algunos casos la lleva a un palacio maravilloso, dentro de la montaña (Ansion, 1987; Bernand, 1985; Escalante y Valderrama, 1997; Ricard, 2007). Cada comunidad, a partir de las visiones y de los sueños personales contado por las jóvenes, localiza la vaguedad del mito y construye una topografía específica de las posiciones de sus puertas y del acceso a su interior.

$\mathrm{Al}$ acercarse a algunos sueños interpretados como manifestaciones del $A p u$, resulta difícil discernir si se trata de experiencias oníricas o cuentos míticos, narrados por las comuneras de Chihua y Contay como si fueran sueños. Esta ambigüedad se nutre, en el plano lingüístico, por la presencia en quechua de un tiempo verbal - denominado pasado narrativoque se utiliza cuando el hablante se refiere a una acción en la cual no ha participado directamente, o no estaba consciente, por ejemplo, cuando cuenta un mito, un sueńo, o un acontecimiento ocurrido cuando estaba ebrio (Itier, 1997). Los sueños como los mitos se transmiten de generación en generación.

\section{Aparecer, desaparecer, esconder}

También a las vacas si el Apu las esconde tampoco las puedes encontrar. Desaparecen totalmente y después aparecen en el mismo lugar. Cuando en el monte la vaca da crías también las esconde, pero ellos mismos [Apu] las sueltan. No sé donde las esconderán, buscas, buscas y no las encuentras.

El verbo "esconder" — en quechua pakay — no se utiliza sólo cuando el Apu hace desaparecer los animales para castigar a quien no respeta el ayni y las ofrendas rituales, sino también cuando engaña a las jóvenes mujeres. 
Y el señor tenía su camisa chiquita y el cabello peinado hacia atrás. Me llamaba desde el fondo del rincón y si yo hubiera estado más cerca seguro me hubiera escondido.

Bello, bello es el interior de la montańa, su casa [del $A p u$ ], tan bella y brillante como la iglesia; se abre, por eso a una muchacha inocente la esconde. ${ }^{14}$

En los testimonios de algunas comuneras, la tentativa del $A p u$ de "esconderlas" parece coincidir con la sensación que ellas experimentan de sentirse perdidas en las montańas. La señora Herminia cuenta de aquella vez en que, habiendo perdido sus cabras, quería ir a buscarlas al monte Antarcacca. Conocía bien aquel lugar y por eso decidió ir en la noche y había preparado leña para encender el fuego al llegar. Mientras caminaba se dio cuenta que ya estaba en el borde del Artarcacca, cuando pensaba estar en Salvia Pampa, pero ya se encontraba en Antarcacca. Seguramente "me ha llevado", comenta, como si la montaña pudiera llevarla y tuviera poder sobre ella para provocarle perder el sentido de orientación, para arrastrarla hacia un lugar sin que ella fuera consciente. Muchas comuneras cuentan haber vivido experiencias similares al estar en la frontera entre el sueño y la vigilia, pensaban que recorrían la senda acostumbrada para regresar a casa y en su lugar se encontraban en otro lugar. Celestina, de Contay, habla de cuando llevaba a pastorear sus ovejas y cayó en cuenta que recorría el mismo camino que había visto en sueños la noche anterior. Cuenta que el camino en que se encontraba era angosto y de pronto se llenó de espinas y agujeros que parecían rodearla e impedirle movimiento alguno. Esta circunstancia fue interpretada por Celestina como un engaño del $A p u$.

El "extraviarse" en las montańas es a veces descrito como una suerte de estado de inconsciencia momentáneo del cual las mujeres se despiertan al oír sonidos del exterior. De hecho, Celestina estaba casi perdida y cuenta que el balido de sus ovejas la despertó. Otra mujer, de un poblado cercano a Contay, narra que cuando era muchachita, mientras hilaba

\footnotetext{
14 "Sumaq sumaq urqutaytapa ukupiqa waisinqa, sumaq sumaq kananallaq kayna igliesi qinas kichakuykun chaysi inusente warmata pakan”.
} 
sola en la montaña, oyó de pronto un sonido como de música y quizás se hubiera "perdido" si una amiga no la hubiera llamado desde lejos; sólo en aquel momento se dio cuenta que estaba al borde de un precipicio.

La expresión "me engañó" se utiliza, en el contexto andino, también para aludir implícitamente a haber tenido una relación sexual y en muchos casos al hecho de haber quedado embarazada (Harvey, 1994). El soñar tener una relación sexual con un hombre gringo puede ser interpretado como un engaño del $A p u$.

En muchas sociedades amazónicas (Descola, 1993), así como en las andinas (Perrin, 1990; Nakashima, 1990), la sexualidad se expresa claramente en los sueños y es considerada una forma de comunicación con espíritus y divinidades o se interpreta en términos sociales como una premonición de alguna conducta o acontecimiento —enfermedad, éxito o fracaso de un proyecto, entre otros-. Es una lógica contraria a la de la sociedad occidental, donde, según el psicoanálisis freudiano, los mensajes sociales de los sueños relevarían una sexualidad omnipresente (Perrin, 1990).

Mientras caminábamos en los altiplanos siguiendo a los animales, mientras desgranábamos mazorcas de maíz sentadas frente a la casa, la narración de sus sueños sexuales se convirtió en la oportunidad de compartir con las comuneras deseos y miedos. Una mañana en la comunidad de Contay, cuando recién habíamos despertado, Alicia, una joven de veinticinco ańos, me contó su sueño de la noche anterior. Estábamos ella y yo en un cuarto y ella me confesaba su preocupación por quedarse embarazada de un muchacho con quien se veía en ese tiempo y que solía insistirle en tener relaciones sexuales. En sueño, yo le hablaba acerca de los anticonceptivos, pero cuando ella pedía alguna explicación, me escondía dentro de un gran sombrero que llevaba en la cabeza.

Aunque en los últimos años médicos ambulatorios reparten gratuitamente algunos métodos anticonceptivos en las comunidades campesinas o en las ciudades de Huanta y Ayacucho, muchas jóvenes se muestran recelosas y continúan identificando el acto sexual con el embarazo, un acontecimiento visto por muchas de ellas como un 
obstáculo, pues les evita salir de la comunidad y construirse una vida distinta en otro lugar.

\section{Las consecuencias del engaño}

A los distintos significados que puede tener el engaño del $A p u$ corresponde una multiplicidad de efectos y consecuencias. Las comuneras de Contay cuentan que cuando los sueños con él se vuelven recurrentes y las mujeres aceptan la seducción de la divinidad, podrían establecer una suerte de pacto matrimonial: el $A p u$, entonces, les donaría muchos animales —que ellas no podrán vender, ni dar como dote-, a cambio tendrían que quedarse solas, no podrán tener marido.

Los comuneros hablan de una mujer que no tenía marido ni hijos y vivía sola en la Puna, en la cima de la montaña Saurama, en contrapartida era dueña de una gran cantidad de animales. Dicen que era la esposa del $A p u$ y que cuando alguien le compraba animales se morían en el camino porque eran propiedad del espíritu de la montaña. De Carmen, una mujer de Contay también sin marido o hijos, se decía lo mismo. Cuando falleció, dejó sus animales a su prima, pero todas las ovejas murieron, acontecimiento que fue explicado por el hecho de que la herencia del $A p u$ desaparece siempre con la muerte de su esposa. Además de la fidelidad de la mujer, la divinidad exige su silencio, y si la mujer habla de sus encuentros la divinidad deja de manifestarse, también la mujer que ha roto el pacto de silencio puede ser castigada con enfermedad o incluso con la muerte.

"Un tiempo habían [sic] muchos opas, porque en ese tiempo muchos $A p u$ se burlaban de las mujeres y las dejaban mudas". La palabra "opa" se utiliza en la doble acepción de "sordo-mudo" y de "estúpido, tonto, atontado" para describir otra posible consecuencia del encuentro con el $A p u$. Un estado parecido a lo descrito por Anne-Christine Taylor (1993) con los Achuar cuando se encuentran en la selva a los iwachi — un tipo de espíritus, una categoría de muertos-, cuya visión provoca un estado de asombro o de atontamiento mudo que se cura por medio del uso del tabaco.

En torno a estas experiencias visionarias y sus posibles consecuencias se ha construido un discurso social: las mujeres que hablan son 
las que aseguran no haber aceptado la seducción de la divinidad. En general, las supuestas esposas del $A p u$ no participan en la construcción del discurso; sus condiciones sociales - el ser solteras, el tener muchos animales, el vivir lejos de la comunidad-y su silencio se tienen por prueba de su pacto secreto con la divinidad.

En algunos contextos culturales tener una relación con esposos o esposas divinas es una de las características del poder de los curanderos (Zolla, 1986). El proceso de aprendizaje del arte de la curación se describe como un matrimonio con una entidad invisible que se manifiesta en sueños y visiones, y les proporciona enseñanzas; sin embargo, en Contay las mujeres de las que se sospecha que han hecho un pacto con el $A p u$ no tienen un papel social parecido al de los curanderos - camayos-. Sus trayectorias de vida se caracterizan por la soledad y su silencio contrasta con el arte oratoria de muchos curanderos, quienes aseguran trabajar con el $A p u$.

A esta chica también en su sueño la hizo embarazarse, pero en su sueño... dicen que el cerro lo hace sólo a quien quiere... pero dicen que Ellos ayudan a la gente pobre pobre y la hacen ricos...

Había en Chihua una mujer que tenía sus ovejas ... ella pastoreaba sus ovejas y en eso ella quedó embarazada porque el cerro se había burlado de ella, y cuando dio a luz murió...

René, una joven comunera de Chihua, cuenta de una niña de su comunidad que había entrado en una gruta para escapar de la lluvia y ahí se había quedado embarazada, entonces mamá Eusebia interviene en la conversación: "son los gentiles [los antepasados] ${ }^{15}$

\footnotetext{
${ }^{15}$ Según la interpretación bíblica, el término "gentil" significa en general una categoría, la de pagano; sin embargo, en los Andes esta palabra alude en particular a una población pre-solar, a una civilización que había reunido un nivel cultural avanzado, pero que después se corrompió. Los gentiles habían dejado de respetar las normas sociales y religiosas, habían infringido los principios de solidaridad y reciprocidad; su codicia fue castigada por una lluvia de fuego "nina para" —en quechua-, que los había hecho desaparecer. Si el mito habla de una ruptura definitiva con esta humanidad corrupta, estos personajes son todavía hoy día llamados "los abuelos", aludiendo a una continuidad genealógica entre las generaciones actuales y estos antepasados míticos. En los relatos de los habitantes de Chihua y de Contay, los gentiles nunca han desaparecido del todo y a través
} 
los que la violaron". En muchos testimonios, la figura del $A p u$ y la de los gentiles se sobreponen, ambos, se dice, pueden seducir y tener relaciones sexuales en sueños con las mujeres que se duermen solas en la montańa. Para engańarlas pueden manifestarse bajo la apariencia de una persona conocida. Los hijos que nacen de estas uniones se caracterizan frecuentemente por padecer malformaciones o por la brevedad de su vida. En estos casos no se habla de un matrimonio con el $A p u$, más bien se utiliza el término "abuso" para explicar algunos embarazos misteriosos. Así Adela describe al hijo de la campesina de Chihua que se dice había sido violada por un gentil:

Sin ano, sin manos, sin pies, él era de color negro, pero con ojitos ... El gentil la violó porque ella se había dormido allá arriba, entre los cactus, arriba de su casa, y se despertó embarazada. ${ }^{16}$

Si la sexualidad y la seducción representaron desde la época prehispánica una de las posibles formas de relación entre las divinidades y los seres humanos, posteriormente formas de engaños similares fueron atribuidas por los evangelizadores a la intervención del diablo (Duviols, 1971). Todavía hoy se contrapone la representación unívoca de la malignidad del diablo a la ambigüedad que caracteriza al $A p u$, y, más ampliamente, a las divinidades del panteón andino. ${ }^{17} \mathrm{El} A p u$ es representado como una entidad que protege a los animales y a los comuneros, al mismo tiempo esta divinidad puede "esconder" a las jóvenes, seducirlas,

de sus huesos se encuentran sobre la montańa, continúan interfiriendo en la vida de las personas. 16 "Mana sikiyuqta, mana makiyuqta, mana chakiyuqta, yana kulluta, pero ñawichayuqta, yuañumi nira. Gintilriki abusarura payta chaysi wasin qanaynipi, huk tuna ukupi puñurusqa, wiksayuq rikurirun".

${ }^{17}$ Como muchos autores han subrayado, la colonización del Perú se diferencia de la de México en la que la presencia de formas de escritura pictográfica conocidas por los aztecas y los mayas permitieron conservar crónicas de la época prehispánica (Gutiérrez, 2001). En el caso del Perú las fuentes escritas surgieron soólo en la época colonial y aún los cronistas autóctonos más importantes — Guamán Poma de Ayala, Garcilaso de la Vega (1615) — eran afectados por la aculturación y sus proyectos historiográficos no pueden ser considerados neutrales, ni una prueba cierta, porque las descripciones que hacen del Estado incaica parecen estar afectadas de una voluntad apologética. Es necesario, por tanto, explicitar el problema de la ambigüedad y fiabilidad de las fuentes para mostrar el carácter hipotético de muchas afirmaciones acerca de las preguntas de los "orígenes" de algunas prácticas y representaciones que todavía hoy circulan en el contexto andino. 
castigarlas con la enfermedad y la muerte. Estos distintos aspectos que caracterizan a la misma divinidad revelan una ambigüedad intrínseca de su poder que nos impide hablar del $A p u$ en términos de un juicio maniqueo bueno-malo (Ansion, 1987; Gose, 1986; Ricard, 2007).

Cuando el $A p u$ es asociado al maligno, al peligro, los relatos sobre su seducción se convierten en una suerte de amonestación que asusta a las jóvenes para que no tengan relaciones sexuales con desconocidos que se encuentren en la montańa. En otros casos, más bien, algunas jóvenes al confiar a sus familiares sus encuentros con el $A p u$ recuerdan que sus padres las regañaron por habérselo contado, porque si no lo hubieran hecho tal vez hubieran recibido dones y riquezas.

Al hablar de estos sueños y visiones las jóvenes rememoran un sentimiento de miedo pero también de fascinación, experimentan lo que Julien Greimas define como "pasiones no polarizadas" (Greimas, 1991), que escapan de la dualidad bueno-malo, como el asombro y la inquietud.

\section{Percibir, interpretar, narrar, revelar}

$\mathrm{Al}$ analizar la concepción del suicidio de los Kashinawa, una población que vive en la Amazonía peruana, la antropóloga Barbara Keifenheim (2002) comenta el proceso de mediación entre la percepción y la interpretación específica en cada cultura. Cuando abandonan el espacio protegido de la comunidad y se adentran a la selva, los Kaschinawa dudan de la fiabilidad de sus percepciones sensibles, este escepticismo está estrechamente vinculado con una concepción del mundo que presupone la existencia de realidades múltiples con interferencias mutuas (Keifenheim, 2002). Por ejemplo, los espíritus de los muertos pueden atraer y seducir a quienes se encuentran en la selva con un olor envolvente o con sonidos, según los Kashinawa, y este contacto auditivo y olfativo engańoso puede impulsar a la persona a abandonar la vida.

Los estímulos perceptivos experimentados en la selva, las visiones, ruidos y olores, tienen que ser descifrados: una estrategia importante para no caer en el error perceptivo es la "combinación intersensorial", es decir, combinar al mismo tiempo las percepciones de la vista, el olor y la audición para comprobar su veracidad. Keifenheim analiza 
la manera en que, según los Kaschinawa, lo "no perceptible" tiene influencia sobre las percepciones. Las almas de los muertos o los lugares pueden emanar substancias — por ejemplo, el "aire" — no perceptibles directamente que atacan al ser humano y sus facultades perceptivas, sin que se percate de ello (Keifenheim, 2002: 96).

En el contexto andino se comparte la idea de que las apariciones y percepciones que se experimentan cuando se está solo en el altiplano pueden ser engañosas y necesitan ser comprobadas e interpretadas. Por ejemplo, cuando se ve a lo lejos a alguien que camina o si nos encontramos de repente frente a una persona, no es seguro que se trate de un ser humano, sino que podría ser la aparición del alma de un muerto o del $A p u$. Oír una voz, ver objetos, sentir que nos golpea un guijarro, experimentar la sensación de perderse o de ser "llevadas" son todas experiencias que, si bien no son comprobadas por una "combinación intersensorial", se interpretan como engaños de la divinidad de la montaña, y sus consecuencias, como se ha visto, pueden ser múltiples.

El concepto de "aire" representa otro elemento común entre el contexto amazónico de los Kaschinawa y el contexto andino, donde se relaciona en algunas ocasiones con el engaño del $A p u$, en otras con el de los gentiles, de los espíritus de los muertos, o de la Pachamama. Las mujeres de la comunidad de Contay describen como esta substancia invisible, una clase de viento que sale de la tierra, puede penetrar en el cuerpo de una persona cuando se adormece en la montańa, provocándole sueños, así como distorsiones en su percepción y en el cuerpo, parálisis, enfermedades y embarazos.

Incierta es la frontera entre sueño y vigilia cuando nos encontramos en la Puna, y esta falta de fiabilidad en las experiencias sensoriales debe situarse en relación con las condiciones del ambiente. Las comuneras que viven en estos lugares, desde su infancia están acostumbradas a pasar mucho tiempo solas, vigilando los animales en altiplanos desiertos, donde la intensidad de la luz, la ausencia de estímulos visuales, la escasa alimentación, el consumo de hojas de coca contribuyen a debilitar los confines entre la ilusión y la realidad.

Estas ilusiones perceptivas, visiones y sueños, similares entre sí, parecen ser producto de las condiciones ambientales y culturales, 
así como de las relaciones de interdependencia ente éstas. Además, los acontecimientos históricos a los que estas montañas han estado sujetas han tenido inevitablemente impacto sobre las experiencias onírico-visionarias y sus interpretaciones. Durante la investigación, junto a los sueños en donde el $A p u$ intenta seducir, me encontré con testimonios de formas de engaño perpetuadas por hacenderos y gringos que detentaron el poder en estos lugares. Hasta hace no muchos años, en el contexto rural andino era común lo que se conoce como "derecho de pernada”, que consistía en la potestad del hacendero para tener relaciones sexuales con las hijas de los campesinos que trabajan para él (Ruiz, 2004: 289). El hacendero se consideraba como dueño no sólo de las tierras, sino también de las personas que trabajaban para él, y las mujeres estaban obligadas a tener relaciones sexuales como forma de "agradar" al patrón y a sus trabajadores de mayor jerarquía; numerosos hijos ilegítimos nacían de estas uniones.

Sea en Chihua o en Contay las comuneras mayores de sesenta años que vivieron su juventud en esa época recuerdan que sus padres no querían nunca mandarlas solas a la hacienda por miedo a que pudieran molestarlas. Los engaños de los hacenderos tomaban forma a partir de una relación de fuerza específica, en estos casos la expresión "engaño" no se refiere a una "pérdida de control” provocada por una alteración perceptiva — producida por el alcohol o una visión y espejismo—, sino más bien debida a un poder de control real ejercido por los hombres gringos sobre los cuerpos de las mujeres campesinas.

Si en Contay muchas mujeres relatan haber experimentado en sueño la seducción o el engaño del $A p u$, ninguna declaró haber sido víctima de abuso sexual real por parte de un gringo; las narraciones se refieren siempre a conocidos y parientes. Las violencias sexuales constituyen un "secreto público" (Taussing, 1987).

Inicialmente, cuando se empezaba a saber sobre los engaños del $A p u$, se intentaba comprender si habían sido realmente experimentados en sueño o se trataba de una forma de justificar acontecimientos reales o de hablar de la violencia sexual, tema tabú en el interior de los poblados. El antropólogo Flores Ochoa (1973) ha sido uno de los primeros científicos en dar una explicación funcionalista a las seducciones y a los 
embarazos atribuidos, en el contexto andino, a fuerzas sobrenaturales que conciernen sobre todo a dos categorías de mujeres: las jóvenes solteras y las viudas. Flores Ochoa concluía su análisis exhortando a los etnólogos a preguntarse si las creencias que ellos encontraban y analizaban en los distintos contextos eran de verdad "reales" o se trataba, más bien, de instrumentos eficaces de control social, en el que la entrada en acción del $A p u$ o del antepasado permitía explicar a la colectividad un comportamiento desviado.

Xavier Ricard (2007) se desprende de la explicación funcionalista de Flores Ochoa para subrayar que, aunque los comuneros no crean que el Apu sea "de facto" responsable del embarazo o de la desaparición de una mujer, al mismo tiempo piensan que en teoría podía haberlo sido. La colectividad sostiene la posibilidad — teórica- de las seducciones del Apu y, de forma más general, de la existencia de distintas entidades que interactúan cotidianamente con los seres humanos. Al tener presente la distinción sugerida por Xavier Ricard entre la responsabilidad "de facto" de las seducciones, desapariciones o embarazos y la posibilidad como "derecho" — de jure—, se puede suponer que, aunque se haga referencia al $A p u$ para justificar una conducta ilegítima o un episodio que perturba la vida comunitaria no por ello se niega la vitalidad de la creencia en la divinidad.

La invisibilidad de los sueños y visiones del $A p u$, así como la imposibilidad de su confirmación, actúan por sí mismas como forma de resistencia a cualquier explicación objetiva y unívoca. Que el $A p u$ sea un espejismo producido por el desierto de la Puna, que sea una entidad que se materializa en los sueños de las mujeres de Contay, que sea una invención mítica para "normalizar" lo anormal, son todas posibilidades copresentes.

La palabra "engaño" en los discursos de muchas mujeres se utiliza a menudo como prueba de su debilidad social, y testimonia el control que se ejerce sobre ellas. Al mismo tiempo, tanto actualmente como en el pasado, recurrir al engaño puede representar también una estrategia para legitimar acciones que violan las reglas de la vida comunitaria. El $A p u$, además de representar una divinidad que domina y tiene comportamientos muy parecidos a los históricamente perpetuados 
por aquellos que detentaron el poder en estos lugares, puede también convertirse en cómplice de los deseos y las acciones de las comuneras.

\section{Desaparecer durante la guerra}

Durante la época de la violencia en las montañas de Ayacucho desaparecieron miles de personas. La experiencia mítica de ser "escondido" por el Apu se convirtió en un evento histórico que golpeó a la colectividad. En la comunidad de Contay, que pertenece a la zona llamada roja, ${ }^{18}$ muchas personas decidieron unirse a las fuerzas armadas del Sendero y nunca más regresaron, asesinados por los militares y enterrados en fosas comunes. Sus cuerpos aún están escondidos en las entrañas de la montaña. Sólo en los últimos años - como resultado de las indicaciones de la Comisión de la Verdad y Reconciliación (CVR), ${ }^{19}$ de la movilización de las asociaciones de los familiares de los desaparecidos y de las ONG de defensa de los derechos humanoslas fosas comunes se han reabierto para intentar esclarecer lo ocurrido aquellos años y para regresar los cuerpos de las víctimas a sus familias (Robin, 2016).

La guerra interna impactó inevitablemente los sueños de las comuneras:

Me matarán diciendo, dentro del barranco sentada lloraba mucho, las armas reventaban ... ni pensaba en mi esposo, estaba como en sueño, totalmente, ni cuenta me daba, entonces seguía sentada, sentada, ni hambre ... así llegué, no habia nadie, como en sueño caminé ... sólo cadáveres... (testimonio CVR). ${ }^{20}$

${ }^{18}$ Contay está situada en el distrito Saurama, provincia Vilchasuamán. El ejército peruano es considerado el principal responsable de las matanzas.

${ }^{19}$ La Comisión de la Verdad fue creada en 2001 con la finalidad de esclarecer lo ocurrido en los años de la violencia. Con el gobierno del presidente Toledo fue renombrada como "Comisión de la Verdad y Reconciliación”. El 28 de agosto de 2003 fue hecho público el Informe final de CVR, compuesto de 12 tomos y 7 anexos, este documento recoge testimonios relativos a las violaciones de los derechos humanos y a las dinámicas de la guerra en 109 provincias de Perú. Los análisis de la Comisión de la Verdad y Reconciliación han sacado a la luz la unidad de una guerra civil que provocó setenta mil víctimas, principalmente campesinos quechua-hablantes que vivían en esta región.

${ }^{20}$ Las narraciones oníricas durante los meses que viví en las comunidades campesinas de Chihua y Contay, en la ciudad de Huanta y Ayacucho, dialogan en este artículo con aquellas 
Estaba como en sueño. ... durante todo ese tiempo estuve dormida, casi desde el año 92 hasta el 98 es como si hubiera estado dormida, era todo una pesadilla (testimonio CVR).

A menudo es la misma realidad de la guerra que se describe con la metáfora onírica: "parecía todo un sueño", "era como un sueño". La expresión quechua "muspaypi quina" es recurrente en los testimonios y ahora cuando las comuneras intentan recordar aquellos años todo parece confuso, e insisten en la dificultad de diferenciar lo que ocurrió "realmente" de lo que sólo sońaron. El peligro de ser engañadas y la falta de fiabilidad en las percepciones se convirtieron en experiencias cotidianas no circunscritas a la soledad de la Puna. Había una sensación de completa irrealidad respecto a aquello que estaba pasando y muchos episodios violentos y traumáticos en los que las personas estuvieron se relatan como una especie de alucinación. En los testimonios, la metáfora de la guerra como un sueño no hace referencia a la experiencia onírica como un lugar de revelación, sino más bien a un estado de confusión y delirio, ${ }^{21}$ y a menudo esta metáfora es acompañada con otras expresiones: "estábamos como locos", "como borrachos". Tal como analiza la antropóloga Kimberly Theidon, no podemos subestimar el papel del alcohol durante la época de la violencia: muchas comuneras empezaron a beber durante aquellos años de guerra para sobreponerse al miedo, para reforzar el alma — animarse - y para darse valor. ${ }^{22}$ "Aprendimos a beber durante aquellos años de violencia", "cuando bebíamos podíamos dormir, el alcohol nos dejaba como muertos, así dormíamos". Estar ebrios les permitía incluso sentir menos dolor y era una forma para prepararse día con día para morir. "Susto", "locura",

encontradas en los archivos de CVR, donde se encuentran centenares de testimonios que hacen referencia a los sueńos.

${ }^{21}$ Antes se ha mencionado que el lingüista Gerald Taylor (2002) a partir de la raíz quechua mus analizó un entrecruce semántico entre la palabra musquy — sońar-, musyay —adivinar- y muspay — delirar- En estos testimonios relativos a la época de la guerra musquy — soñarparece acercarse más al muspay — delirar—que al musyay —adivinar.

${ }^{22}$ Hoy es justo cuando hombres y mujeres se embriagan que se acuerdan de los años de la guerra y es en esos momentos que se reviven los conflictos y resucitan las acusaciones recíprocas de "terrucos" o "soplones". El alcohol se convierte al mismo tiempo en un medio para olvidar, pero también para recordar (Theidon, 2004). 
"sueño", "borrachera", son las palabras más recurrentes con las cuales se describen aquellos años (Theidon, 2004).

Que la guerra sea descrita como una experiencia alucinatoria no es sólo una característica del contexto andino. Al referirse de los regímenes totalitarios de terror presentes en muchos estados del África contemporánea, en particular en el este del Congo, Roberto Beneduce evidencia como "las semánticas de lo invisible, de lo onírico, de lo grotesco, de lo mágico y de lo ritual se entretejen sin soluciones de continuidad a aquello de lo político" (Beneduce, 2008: 180). La instrumentalización de lo que Walter Benjamin designaba "crisis de la percepción" 23 , ha sido analizada por Hanna Arendt (1999) dentro del Sistema Totalitario. Para mantener a los dominados en un estado de constante alerta, los miembros del régimen habían construido un ambiente en el que no había distinción entre lo verdadero y lo falso, entre realidad y ficción, así la locura "artificialmente fabricada" (Arendt, 1999) se convertía en algo más probable que la realidad. La eficacia del mecanismo de represión se fundaba en el miedo y la sospecha que se instalaba en cada individuo.

También en el contexto andino, la negación de los acontecimientos, la impunidad, los silencios impuestos, la presencia de mensajes contradictorios alimentaron este sentido de irrealidad ante las atrocidades del conflicto (Theidon, 2004). Un militar que se había dirigido a un grupo de campesinos decía: "Quédense con sus hijos y vaya cada uno a su casa, hagan como si todo esto hubiera sido un sueño" (testimonio, CVR).

Durante esta guerra "como de sueño", las manifestaciones del $A p u$ se entretejen con testimonios de los acontecimientos. ${ }^{24}$ A la viuda del curandero de Chihua, el $A p u$, bajo la forma de un hombre blanco, le dijo en sueños que no debía huir, sino quedarse en la comunidad porque él la protegería. Y es por eso que Eusebia dice haberse quedado

${ }^{23}$ Benjamin, Walter, 2000 [1939], "Sur quelques thèmes baudelairiens", in Euvres III, Trad. de l'allemand par Maurice de Gandillac, Rainer Rochliz et Pierre Rusch, Gallimard, Paris, pp. 377-378.

${ }^{24}$ Gose (1986) recuerda que el culto de los $A p u$ también en el pasado transmitió reivindicaciones políticas de los campesinos. Cita las investigaciones de Langer (1990) y Platt (1983) que analizaron cómo en una revuelta en Chayanta en 1927, los Apu — con la mediación de los curanderosfueron consultados y fueron considerados verdaderos guías en la rebelión contra los latifundistas. 
en la comunidad, aunque en varias ocasiones haya sido golpeada y amenazada por los senderistas. Es cierto que muchas comuneras y comuneros que apoyaron la revuelta recurrieron a las ofrendas rituales para obtener la protección de la montaña; sin embargo, en otros casos estas mismas ofrendas y creencias fueron instrumentalizadas por quien no creía en el $A p u$, pero conocía su importancia en la cultura andina. Muchos integrantes de Sendero no eran campesinos, sino profesores y estudiantes provenientes de contextos urbanos. Aunque la ideología maoísta obligara a alejarse de la religiosidad andina, considerada un legado arcaico del cual debían librarse, algunas de estas mismas creencias fueron utilizadas por los integrantes de Sendero Luminoso para engañar a los campesinos y convencerlos de participar en la revolución. Incluso en el documento final de CVR encontramos testimonios que recordaban cómo los Senderistas durante las asambleas públicas expresaban su alianza con el $A p u$ : "Para nosotros hablan las piedras, las rocas; todo lo que hacen ustedes nosotros [lo] estamos viendo" (testimonio CVR).

En el teatro de la violencia, las prevaricaciones y las violaciones sexuales en contra de las comuneras fueron una práctica generalizada perpetrada por el ejército. ${ }^{25}$ Sin embargo, la Comisión de la Verdad y Reconciliación al intentar aclarar los innumerables casos de violación se ha topado con el silencio de las mujeres. Si durante la época de la violencia el silencio había sido impuesto y había sido imposible denunciar los abusos cometidos por los militares, hoy el silencio es funcional para el mantenimiento del orden colectivo — familiar y comunitario-. Las mujeres que rompieron el silencio y que testimoniaron haber sido violadas, a menudo se encuentran viviendo el estigma y la condena por parte de sus mismos esposos, que las desprecian, así como a los hijos que nacieron de aquellas situaciones. Para los esposos y los padres el no haber podido reaccionar ante aquellas violencias y el no haber podido obtener justicia parece haber generado una especie de procedimiento de negación. En el archivo de la Comisión de la Comisión de la Verdad y Reconciliación encontramos el testimonio de una mujer de Saurama - comunidad campesina cerca de Contay- que denuncia por lo

\footnotetext{
25 También los integrantes de las rondas campesinas y los Senderistas han sido acusados de cometer abusos sexuales, pero no se trataba de una estrategia generalizada como aquellas perpetradas por el ejército y la marina.
} 
menos treinta casos de violación sexual ocurridos en su poblado y en poblados vecinos, perpetrados por militares de la base Vilcashuaman. Cuenta que cuando llegaron a Saurama los soldados y reunieron a los comuneros en la plaza dijeron que un médico daría consulta gratuita a todos. Los hombres y las mujeres fueron separados y estas últimas fueron llevadas a una habitación donde las violaron, ${ }^{26}$ pero ninguna mujer de Saurama o de Contay ha contado nunca en primera persona el haber sido abusada por los militares.

Por otra parte, encontré en las comunidades narraciones sobre sueños que tenían por protagonistas a militares que intentaban agredir y violar sexualmente a las comuneras, interpretados como una manifestación del $A p u$ y como premoniciones de una enfermedad llamada daño de $A p u$, causada por el contacto físico con un lugar peligroso "malo" de la montaña o por no haber respectado las reglas de reciprocidad.

En mi sueño mi esposo me decía que hay una citación, y yo tengo que ir. Yo estaba yendo, cubierta con el poncho, y vinieron dos militares, primero me agarraron y vieron mi rostro. Ellos me dicen: "quiero dormir contigo para acostarnos", así me dicen..., yo empecé a gritar, a gritar llorando, allí me soltaron ... eso he sońado para enfermarme.

El Apu Piuchu dicen que es sinchis. ${ }^{27}$ En el medio de la niebla, cuando él quiere te aparece bajo la apariencia de jóvenes militares. ${ }^{28}$

Cuando sueñas con guardias que te disparan o te violan en eso te daña tu cuerpo. Empiezas a sentir que te duele el cuerpo, es por eso que también sueñas militares, es así que nos damos cuenta si nos vamos a enfermar o no.

\footnotetext{
26 "Llegaron los militares y nos reunieron en la plaza de armas, luego separaron a hombres y mujeres, diciendo que un médico nos va a examinar gratis, nos hacían ingresar una por una al local de la escuela, cuando una señora se dio cuenta era para violarnos..." (Testimonio, CVR). ${ }^{27}$ Sinchis es el nombre de un cuerpo especial de militares presentes durante la época de la guerra. 28 "Piuchusinchis chayqa, puyu puyukun chaypi paypi, rikurisuykita munan jovenkuna formakun guardiakuna”.
} 
Al contar estos sueños, las comuneras no hacen referencia a los recuerdos y a los traumas dejados por la guerra, más bien se preguntan acerca del lugar donde han dormido o se han sentado y a dónde llevarán un pagapu para restablecer el equilibrio con la divinidad de la montańa. La escena onírica en la que la violencia de los gringos y de los militares se presenta en la misma forma que en la realidad, no se interpreta con el significado y el contenido del sueño, más bien como un símbolo que necesita ser decodificado, reconduciendo al sueño hacia una trama mítica, donde parece encontrar sentido y una resolución ritual.

\section{Para concluir}

Sentado a la entrada de la puerta de su casa, Tío Cirilo observa las montañas delante de Contay y me dice sus nombres. Cuando me hablaba del poder del $A p u$, Tío Cirilo subrayaba la distinción entre montañas vivas como las de allá, me indicaba con las manos, y las de Lima que se han debilitado bajo el peso de las casas. Ahí es el ser humano que venció y que manda a la montaña. Cuando los campesinos vivían aislados, las manifestaciones del $A p u$ eran más frecuentes: "ahora no, dado que nosotros [las personas] nos hemos multiplicado, el $A p u$ no aparece más”29.

De acuerdo con los comuneros, mientras más deshabitada y salvaje está la montaña, más se manifiesta su poder sobre los seres humanos; con el crecimiento de los poblados la potencia del $A p u$ y sus apariciones disminuyen. Anita, una campesina de Contay, contaba que una vez, mientras buscaba madera pasó a aquel lugar — donde se encuentra una de las bocas de la montaña-y para describirlo usaba la expresión "estaba riendo" — asirayachkasqa —. Una vez recibida la ofrenda, la boca del Apu volvía a cerrarse por un tiempo — sipukurun—, pero en los últimos tiempos ella no sabe dónde ir a llevar las ofrendas, porque aquella boca parece haberse cerrado definitivamente.

También Rashuilca, considerada la montaña más importante de la región de Ayacucho, se considera hoy "empobrecida", "amansada" $y$ “achicada” (Del Pino, 2017), además por causa de los cambios climáticos, "las fiebres de las montańas" han provocado el deshielo de los nevados y la pérdida de recursos naturales.

\footnotetext{
29 "Manañachiki, runachikilliw mirarunchik hinaptin pay mana rikurinchu".
} 
Las trasformaciones religiosas, ${ }^{30}$ la época de la violencia y el fenómeno de la urbanización, son otros factores que inciden en la relación entre comuneras y la montańa. Son precisamente los sueños los que llevan a dudar acerca de la existencia del $A p u$ a las jóvenes, que afirman ya no creer en la divinidad. Los sueños se convierten en vehículo de transmisión de creencias y memorias transgeneracionales.

Al principio, ante los testimonios de los sueños y de los engaños del $A p u$, yo buscaba su secreto o la verdad que se escondía detrás de aquellas narraciones. Trataba de comprender si podrían ser fruto de una experiencia visionaria vivida, o si representaban más bien narraciones míticas, o una manera de justificar y hablar de episodios ocurridos. El Apu podía aparecer como gringo, como sinchis o como militar también antes de la época de la hacienda y de la guerra interna. Sin querer sugerir una relación de causa/efecto entre esos sueños y la época de la hacienda y del conflicto armado, se puede observar como las narraciones que hablan de los engaños y de las violaciones sexuales oníricas contrastan con el silencio que rodea este tema tabú en el contexto comunitario. Es precisamente al poner en diálogo las narraciones de los sueños con los mitos y la historia que he caído en cuenta como las muchas interconexiones entre la experiencia perceptiva, las condiciones ambientales, las narraciones míticas, los acontecimientos históricos, las prácticas y las estrategias sociales, han estado todos copresentes y al mismo tiempo no excluyeran la posibilidad de que las mujeres de la comunidad de Contay soñaran con el $A p u$ y creyeran en su potestad de manifestarse para seducirlas y engañarlas mientras dormían o al estar despiertas. Así como es reduccionista desmitificar estas narraciones oníricas y míticas, sería igualmente limitado considerarlas experiencias y creencias que no tienen ninguna relación con las prácticas sociales y la historia. Los sueños encontrados en las montañas andinas no son sólo expresión de las subjetividades de las comuneras, son también espejo de una vivencia colectiva y muestran que sus contenidos, sus interpretaciones, así como

\footnotetext{
${ }^{30}$ A partir de 1980 los movimientos protestantes y evangélicos de varios tipos han comenzado a difundirse en estas montańas, trayendo consigo lo llamado por Wachtel (2001) como la segunda campaña de extirpación de la idolatría. Una verdadera batalla contra el Apú, asimilado al demonio, ha sido entablada por muchos pastores evangélicos que disuaden a las personas de recurrir a los camayos para invocar a la montaña y celebrarle ofrendas rituales.
} 
la misma naturaleza de la experiencia onírica, están profundamente influidos por el contexto ambiental y sociocultural.

\section{Bibliografía citada}

Absi, Pascale, 2003, Les ministres du diable. Le travail et ses représentations dans les mines de Potosí, Bolivie, L'Harmattan, Paris.

Ansion, Juan, 1987, Desde el rincón de los muertos: el pensamiento mitico en Ayacucho, Gredes Editor, Lima.

Arendt, Hanna, 1999 [1962], Le origini del totalitarismo, Edizioni di Comunità, Torino.

Arriaga, Pablo José, 1968 [1621], Extirpación de la idolatría del Perú, Biblioteca de Autores Españoles, Madrid.

Beneduce, Roberto, 2008, "Semantiche del terrore, della morte e della speranza nell'Est del Congo", Antropologia, n. Violenza, Meltemi editore, Milano.

Benjamin, Walter, 2000 [1939], "Sur quelques thèmes baudelairiens", in Euvres III, Trad. de l'allemand par Maurice de Gandillac, Rainer Rochliz et Pierre Rusch, Gallimard, Paris, pp. 377-378.

Bernand, Carmen, 1985, La solitudes des Renaissantes: malheurs et sorcellerie dans les Andes, Presse de la Renaissance, Paris.

Cobo, Bernabé, 1964 [1653], Historia del Nuevo Mundo, Biblioteca de Autores Españoles, tomos 91 y 92, Madrid.

Del Pino, Ponciano, 2017, En nombre del gobierno. El Perú y Uchuraccay: un siglo de politica campesina, La Siniestra Ensayos, UNJ, Lima.

Descola, Philippe, 1993, Les lances du crépuscule, Terre Humaine-Plon, Paris.

Duviols, Pierre, 1971, La lutte contre les religions autocthones dans le Pérou colonial: L'extirpation de l'idolâtrie entre 1532 et 1660, Institut Français d'Etudes Andines, Lima-Paris.

Escalante, Carmen y Ricardo Valderrama, 1997, La doncella sacrificada, UNSA, IFEA Editores, Arequipa.

Favre, Henri, 1967, "Tayta Wamani: Le culte des Montagnes dans le centre sud des Andes Péruviennes", Etudes Latino-Américaines III, pp. 120-141. 
Flores Ochoa, Jorge, 1973, "La viuda y el hijo de soq'a machu", Allpanchis, núm. 3.

Gose, P., 1986, "Sacrifice and the Commodity Form in the Andes", Man, New Series, vol. 21, núm. 2, jun., pp. 296-310.

Greimas, Julien, 1991, Sémiotique des passions: des états des choses aux états d'âme, Editions du Seuils, Paris.

Gruzinski, Serge, 1988, La colonisation de l'imaginaire: sociétés indigènes et occidentalisation dans le Mexique espagnol, XVIe-XVIIIe siècle, Gallimard, Paris.

Guaman Poma de Ayala, Felipe, 1936, Primer nueva corónica y bven gobierno (1615), Edición facsimilar, Instituto de Etnología, Paris.

Gutiérrez, Manuel, 2001, "Las differencias contra la mitologia", en M. León Portilla, M. Gutiérrez y G. Gossen (editores), Motivos de la antropologia americanista, FCE, México, pp. 327-365.

Harvey, Penelope, 1994, "Domestic violence in the Peruvian Andes", in Harvey, P. y P. Gow (editors), Sex and Violence: Issues in representation and experience, Routledge, London and New York, pp. 66-89.

Itier, Cesar, 1997, Parlons Quechua: la langue du Cuzco, L'Harmattan, Paris.

Jiménez Borja, Arturo, 1961, "La noche y el Sueño en el Antiguo Perú", Revista del Museo Nacional, tomo XXX, pp. 85-95, Lima.

Keifenheim, Barbara, 2002, "Suicide à la kashinawa: le désir de l'au-delà ou la séduction olfactive et auditive par les esprits des morts", Journal de la Société des Américanistes, núm. 88, pp. 91-110.

Langer, Erick, 1990, "Andean rituals of revolt: the Chayanta rebellion of 1927”, Ethnohistory, vol. 37, núm. 3, pp. 227-253.

Mannheim, Bruce, 1987, "A semiotic of Andean dreams", in Tedlock, B. (editor), Dreaming: Anthropological and Psychological Interpretations, Cambridge University Press, Cambridge, pp. 132-154.

Molinié, Antoinette, 1992, "La vision dans les Andes aujourd'hui", in J. Sallmann (sous la direction), Visions indiennes, visions baroques: les métissages de l'incoscient, Puf, Paris, pp. 185-213.

Nakashima, Lydia, 1990, "Punkurre y Punfuta: los cónyugues nocturnos. Pesadillas y terrores nocturnos entre los Mapuche de Chile", en 
M. Perrin (editor), Antropología y experiencia del sueño, AbyaYala, Quito, pp. 179-193.

Perrin, Michel (editor), 1990, Antropologia y experiencias del sueño, Ediciones Abya-Yala, Quito.

Platt, Tristan, 1983, "Conciencia andina y conciencia proletaria: quyaruna y ayullu en el Norte de Potosî", HISLA: Revista Latinoamericana de Historia Económica y Social, núm. 2, pp. 47-73.

Ricard, Xavier, 2007, Ladrones de Sombra: El universo religioso de los pastores del Ausangate (Andes superuanos), Instituto Francés de Estudios Andinos, Centro Bartolomé de las Casas, Lima, Cuzco.

Robin Azevedo, Valérie, 2008, Miroirs de l'autre vie: Pratiques rituelles et discours sur les morts dans les Andes de Cusco (Pérou), Société d'Ethnologie, Nanterre.

Robin Azevedo, Valérie, 2016, "Rendre leur dignité aux disparus de la guerre? Exhumations, justice réparatrice et politique de la compassion au Pérou", in Anne-Marie Losonczy et Valérie Robin Azevedo (dirs.), Retours des corps, parcours des ames, Editions Petra, Paris, pp. 75-101.

Ruiz Bravo, Patricia, 2004, "Andinas y criollas: identidades femininas en el medio rural peruano", en N. Fuller (ed.), Jerarquias en Jaque: Estudios de género en el aréa andina, IEP, Lima.

Taussig, Michael, 1987, Schamanism, Colonialism and the Wildman, University of Chicago Press, Chicago.

Taylor, Christine, 1993, "Des Fantômes stupéfiant”, L'Homme, tomo XXXIII (2-4), núm. 126-128, pp. 429-447, avr-déc.

Taylor, Gerald, 2002, Sermones y exemplos: Antología bilingue castellanoquechua. Siglo XVII, IFEA, Lima.

Theidon, Kimberly, 2004, Entre prójimos: el conflicto armado interno y la politica de la reconciliación en el Perú, IEP Ediciones, Lima.

Wachtel, Nathan, 2001, El Regreso de los Antepasados. Los indios Urus de Bolivia, del siglo XX al XVI, Fondo de Cultura Económica, México.

Zolla, Elémire, 1986, L'amante invisibile. L'erotica sciamanica nelle religioni, nella letteratura e nella legittimazione politica, Marsilio, Venezia. 